\title{
PROJETO “MEIO AMBIENTE E CIDADANIA" - COMO FERRAMENTA DE TRANSFORMAÇÃO E APOIO AO PROGRAMA DE GESTÃO AMBIENTAL NO MUNICÍPIO DE JAGUARI/RS
}

\author{
Andrea Pereira Lock'; Anna Christine Ferreira Kist ${ }^{2}$ \\ 1 Especialista em Educação Ambiental, Mestranda do Programa de Pós-Graduação em Geografia e Geociências, UFSM, \\ andrea p lock@hotmail.com ; \\ 2 Especialista em Educação Ambiental, Mestre em Geografia e Geociências, Acadêmica do curso de Geografia \\ Bacharelado, UFSM, afkist@yahoo.com
}

\section{RESUMO}

A Educação Ambiental é considerada, neste trabalho, uma ferramenta de transformação social, sendo desenvolvida através de uma educação dialógica, participativa e emancipatória, proporcionando o desenvolvimento de educadores ambientais críticos aptos a decidir e atuar nas escolas frente a realidade socioambiental vivenciada na atualidade. $O$ projeto "Meio Ambiente e Cidadania" foi realizado a partir do Convênio de Cooperação Técnica e Consultoria Ambiental entre a Fundação MO'Ã - Estudos e Pesquisas para a Proteção e o Desenvolvimento Ambiental e o Município de Jaguari - RS. Este Projeto teve como objetivo geral auxiliar na formação de educadores ambientais para a construção da Agenda Ambiental nas Escolas Municipais. Os objetivos específicos foram: Estimular o debate acerca dos problemas e potencialidades existentes no Município; Contribuir na formação e qualificação de educadores ambientais com a finalidade de potencializar os esforços do núcleo formador e Promover por meio de uma formação teóricometodológica qualificada, a reflexão e proposição pelos professores de práticas educativas ambientais para o enfrentamento das questões sócio-ambientais vividas pela comunidade escolar. A metodologia buscou a dialogicidade, onde os temas, as propostas, as atividades serão com base na metodologia da Pesquisa Ação, tendo como referências teóricas Michel Thiollent, onde o grupo desempenha um papel ativo na própria realidade dos fatos observados e nas mudanças que se pretende alcançar, promovendo a melhoria da qualidade de vida da população local. Ralizou-se encontros, proporcionando espaços de diálogo, a partir de reflexões coletivas, explanações teórico-metodológicas, estudos de caso, discussão de textos e práticas educativas ambientais que permitiram unir a qualificação teórica com a experiência prática do grupo de professores participantes. Estes momentos presenciais, somados ao trabalho que os educadores desenvolvem nas suas respectivas escolas permitirão ao município contar com um grupo de educadores ambientais aptos a propor e desenvolverem práticas ambientais transformadoras e multidisciplinares, a partir das diferentes realidades escolares.

Palavras-chave: Educação Ambiental, Práticas Ambientais, Meio Ambiente, Cidadania

\section{INTRODUÇÃO}

Este projeto foi desenvolvido a partir do Convênio de Cooperação Técnica e Consultoria Ambiental firmado entre a Fundação MO'Ã e o Município de Jaguari - RS em Setembro de 2010, a fim de promover o desenvolvimento de atividades de Educação Ambiental para a comunidade, visando auxiliar na defesa do equilíbrio do meio ambiente. 
O presente projeto realizou-se no 20 semestre de 2010 e 1 o semestre de 2011 , o objetivo geral deste trabalho foi auxiliar na formação de educadores ambientais para a construção da Agenda Ambiental nas Escolas Municipais. Os objetivos específicos foram: Estimular o debate acerca dos problemas e potencialidades existentes no Município; Contribuir na formação e qualificação de educadores ambientais com a finalidade de potencializar os esforços do núcleo formador e promover por meio de uma formação teórico-metodológica qualificada, a reflexão e proposição pelos professores de práticas educativas ambientais para o enfrentamento das questões sócio-ambientais vividas pela comunidade escolar.

O Município de Jaguari localiza-se no Estado do Rio Grande do Sul, fazendo parte da Mesorregião Centro Ocidental Rio-Grandense, Microrregião Santa Maria, possui uma área de $673.459 \mathrm{~km}^{2}$ e densidade demográfica de 18,3 hab./ $\mathrm{km}^{2}$. Limita-se geograficamente com os municípios de São Vicente do Sul, Mata, Jari, Santiago, Nova Esperança do Sul e São Francisco de Assis.

A população estimada em 2006 é de 12.295 habitantes, destes aproximadamente $50 \%$ residem na cidade. Jaguari possui clima temperado e relevo bastante acidentado, entremeado de vales, cerros e chapadas, guardando uma das mais belas paisagens da região. A base econômica do Município é a agricultura e a pecuária. O município é banhado pelo rio Jaguari, afluente do rio Ibicuí. Constitui-se em um Município conhecido por "Terra das Belezas Naturais". Estes cognomes mostram o verdadeiro perfil do município quanto as suas potencialidades turísticas, que atraem e cativam os visitantes.

O Município além de belezas naturais possui diversos problemas ligados diretamente as questões socioambientais, entre eles a problemática dos resíduos sólidos. Para que se estabeleça um gerenciamento integrado de resíduos sólidos tanto na zona urbana quanto na zona rural é fundamental o desenvolvimento de um processo de educação ambiental na perspectiva crítica da educação ambiental, interligando a educação ambiental formal com a não-formal, criando um elo entre a escola e a comunidade.

\section{METODOLOGIA}

Está pesquisa foi desenvolvida com base na metodologia da pesquisa-ação, segundo Thiollent (1996), optou-se pela escolha deste método de pesquisa, devido ao fato do mesmo considerar relevância a inter-relação entre o pesquisador e os sujeitos participantes da pesquisa, visto que nesta metodologia não são os sujeitos que são pesquisados, mas a situação em que se encontra, seu modo de pensar, agir, o contexto em que estão inseridos. Os objetivos da pesquisaação não se limitam apenas à descrição ou à avaliação, mas ao conhecimento associado à ação em busca da transformação da realidade.

Utilizou-se como tema gerador os resíduos sólidos, segundo as idéias expostas por Freire (1987) buscando o desenvolvimento deste através de uma abordagem crítica da educação ambiental, conforme Isaia (2004). Como instrumentos de investigação foram utilizados a dialogicidade, entrevistas, questionários com o objetivo de desenvolver um panorama da realidade da educação ambiental nas escolas do Município e das práticas desenvolvidas em educação ambiental pelos professores.

O trabalho foi realizado em etapas:

Primeiramente, fez-se uma revisão bibliográfica referente aos temas apresentados, com o objetivo da construção de um referencial teórico e metodológico para o desenvolvimento do 
trabalho, os temas pesquisados nortearam três eixos importantes, a Educação Ambiental, Resíduos Sólidos e Práticas Ambientais.

Num segundo momento, foi estabelecido contato com a Secretaria de Planejamento e Meio Ambiente, tendo em vista que os trabalhos com o município de Jaguari ocorreram inicialmente através desta secretaria, na realização de um curso de qualificação para os catadores da Associação de Recicladores Profetas da Ecologia - ARPEJ. Nesta etapa ocorreram as primeiras reuniões integrando a Secretaria de Planejamento, a Fundação MO'Ã e a Secretaria de Educação com o objetivo de delinear e construir as primeiras ações a serem realizadas.

No terceiro momento, foi estabelecido contato com os coordenadores, diretores das escolas e professores através da reunião pedagógica do Município que contou com a participação de todos os professores da Rede Municipal de Educação e gestores, participando também neste evento a Secretaria de Planejamento e Meio Ambiente e a Bióloga desta secretaria. Neste encontro o objetivo da nossa intervenção foi de participar da construção do planejamento para o ano letivo, apresentação da Fundação MO'Ã, dos seus representantes e da proposta de trabalho a ser desenvolvida.

Num quarto momento foi realizada uma visita a cada uma das escolas e estabelecido um contato direto com os diretores e coordenadores das mesmas, com o intuito de pesquisar as práticas pedagógicas desenvolvidas em educação ambiental na instituição e a realidade em que se encontra a mesma tanto em relação ao meio ambiente escolar como também a comunidade em que esta inserida. Utilizou-se como instrumento de investigação o diálogo, entrevista e a observação.

No quinto momento, realizou-se a tabulação e análise dos dados coletados.

Num sexto momento realizou-se uma reunião com as secretarias de Educação e com a de Planejamento e Meio Ambiente com o objetivo de apresentar os resultados obtidos nas visitas às escolas, a análise dos dados coletados e a construção em conjunto das atividades a serem desenvolvidas como também definição da próxima ação a ser realizada.

No último momento, buscou-se a integração dos professores no processo educativo através da participação dos mesmos, utilizando como instrumento a realização da I Jornada Municipal de Educação Ambiental, uma promoção e realização da Prefeitura de Jaguari através das Secretarias de Educação, de Planejamento e Meio Ambiente e Fundação MO'Ã. A programação do evento e a metodologia utilizada foi com base nas práticas educativas emancipatórias, políticas públicas de educação ambiental e meio ambiente, como também na Política Nacional de Resíduos Sólidos.

Abaixo (QUADRO 1) encontra-se descrito as temáticas e a programação realizadas na Jornada de Educação Ambiental.

I JORNADA MUNICIPAL DE EDUCAÇÃO AMBIENTAL DE JAGUARI

TEMA: "EDUCAR PARA A SUSTENTABILIDADE"

DATA : 7 de Julho de 2011

LOCAL: Auditório da Escola Municipal Guilhermina

Município de Jaguari - RS 


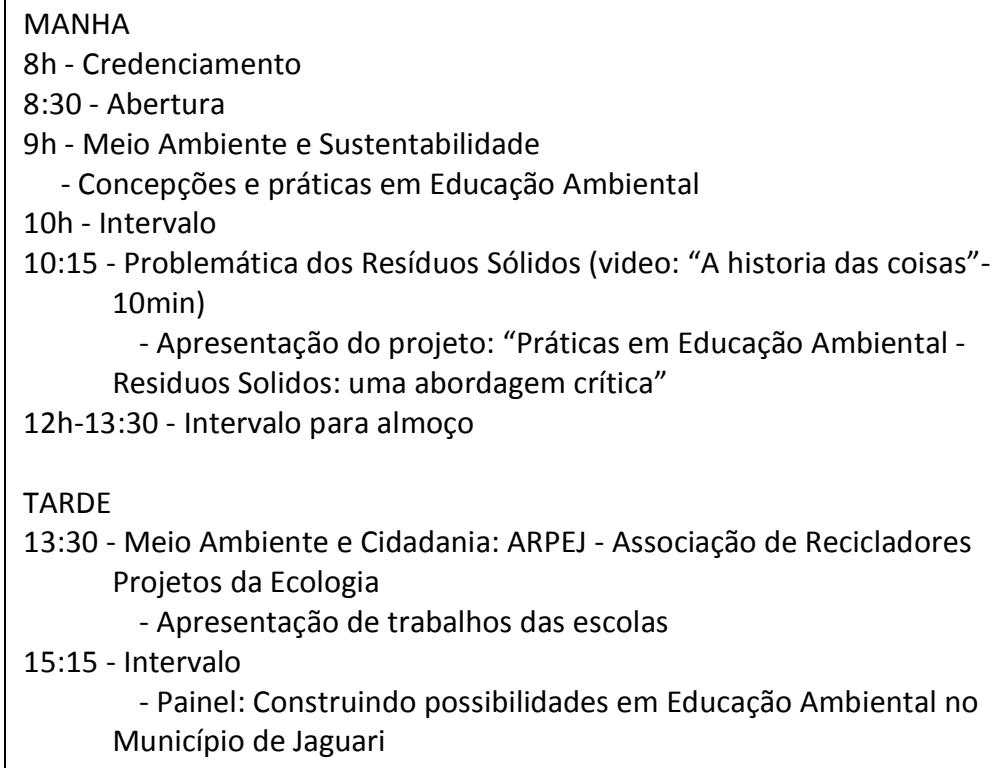

QUADRO 1: Jornada de Educação Ambiental

Elaborado por: Lock. A.P; Kist. A.C.F.

\section{RESULTADOS E DISCUSSÃO}

A educação ambiental é entendida através de processos em que o indivíduo e a coletividade constroem valores, conhecimentos, habilidades, atitudes e competências voltadas para a preservação e conservação do meio ambiente, bem de uso comum do povo essencial a sadia qualidade de vida e sua sustentabilidade (BRASIL, 1999).

Em relação às políticas públicas do país relacionadas às questões ambientais, em especial em atendimento ao artigo 8ㅇ da Lei Federal no 9.795, de 27 de abril de 1999 que institui a Política Nacional de Educação Ambiental (BRASIL, 1999), e da Política Nacional dos Resíduos Sólidos, podemos destacar que o município de Jaguari apresenta diversas ações e projetos que significam um grande avanço nas questões relacionadas aos resíduos sólidos, como também a educação ambiental.

As primeiras ações realizadas foram através de reuniões com representantes da Secretaria de Educação e da Secretaria de Planejamento e Meio Ambiente do Município de Jaguari (Conforme Figura 1), Associação de Recicladores Profetas da Ecologia - ARPEJ, Professores da Rede Municipal de Ensino e representantes da Fundação MO'Ã, como também foi realizado visitas nas escolas (conforme Figura 2), estabelecendo espaços de reflexão e ação. Uma das atividades do projeto Meio Ambiente e Cidadania compreenderam na realização de um curso de capacitação aos integrantes da ARPEJ e familiares, abrangendo questões técnicas, educacionais e socioambientais. Buscou-se a realização das atividades, a avaliação dos trabalhos desenvolvidos e o compartilhamento de experiências a partir de reflexões coletivas, estudos de caso, discussão de 


\section{LOCK \& KIST, vol.(5), n5, p. 1107 - 1114, 2012. \\ Monografias Ambientais issN: 2236-1308}

textos e atividades práticas que permitiram unir a qualificação teórica com a prática do grupo, através de uma Educação Ambiental - crítica e transformadora.

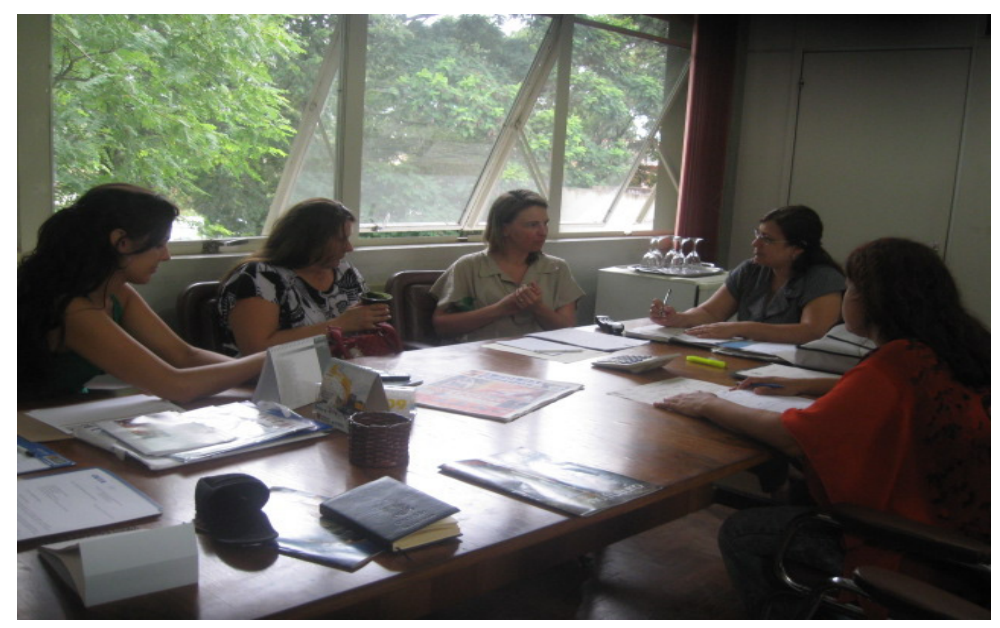

FIGURA 1: Reunião com Secretaria de Educação - Nov/2010 FONTE: Lock. A.P; Kist. A.C.F.

Em relação à Secretaria de Educação, pode-se observar que a mesma não possui um responsável que coordene a educação ambiental e estabeleça diretrizes e políticas, como também orientações para o estabelecimento da educação ambiental nas escolas de sua abrangência. Um dos resultados obtidos foi relacionado à constatação pela secretaria da necessidade de estabelecer um espaço para a educação ambiental na mesma, proporcionando diretrizes, orientações entre outros.

Conforme as coordenações e direção das escolas os projetos político-pedagógicos das mesmas se propõem a realização de um trabalho alinhado à tendência crítica dos conteúdos, fato que poderia proporcionar o bom desenvolvimento da abordagem crítica da educação ambiental na prática pedagógica da escola. Com as visitas as escolas e entrevistas com os gestores pode-se observar uma fragmentação e diversidade tanto em relação à realidade socioambiental das escolas quanto às práticas educativas dos professores.

A Educação Ambiental, numa perspectiva crítica, tem a tarefa de problematizar as questões que dizem respeito ao exercício da cidadania, com vistas a garantir a sustentabilidade, com justiça socioambiental. Segundo (CARVALHO, 2006, p. 37):

A visão socioambiental orienta-se por uma racionalidade complexa e interdisciplinar e pensa o meio ambiente não como sinônimo da natureza intocada, mas como um campo de interações entre a cultura, sociedade e a base física e biológica dos processos vitais, no qual todos os termos dessa relação se modificam dinâmica e mutuamente.

O processo de educação ambiental é um fator extremamente relevante para a defesa do meio ambiente, destaca-se que a mesma na sua maioria é abordada de forma isolada e individual, reforçando e impulsionando a ação pontual e a abstenção de muitos da sua responsabilidade em defesa do meio ambiente. Diante disso, nesta questão observa-se que as políticas públicas e projetos ambientais encontram-se na prática fragmentados e alterados conforme a gestão 
municipal, onde muitas ações e projetos iniciados não são dados continuidade, este é um fator político que impede o desenvolvimento e a transformação da realidade socioambiental. A partir desta, observa-se a necessidade da efetivação de políticas públicas ambientais permanentes e independentes do governo instituído.

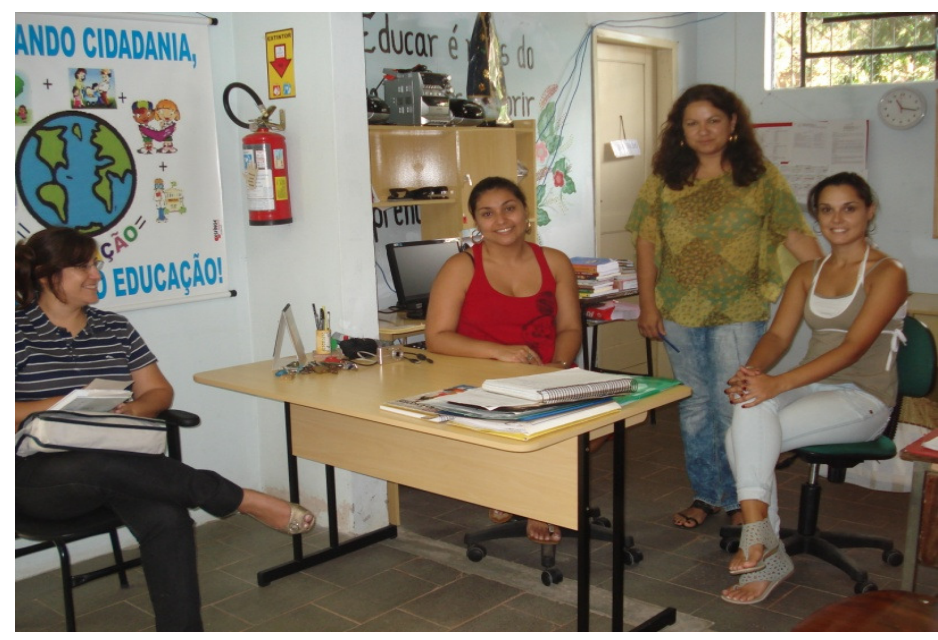

FIGURA 3: Visita a Escola - Março /2011

FONTE: Lock. A.P; Kist. A.C.F.

Em relação às políticas públicas na área ambiental pode-se destacar o capítulo VI, art. 225, da Constituição Federal, Art. 225:

Todos têm direito ao meio ambiente ecologicamente equilibrado, bem de uso comum do povo e essencial à sadia qualidade de vida, impondo-se ao poder público e à coletividade o dever de defendê-lo e preservá-lo para às presentes e futuras gerações.

VI - promover a educação ambiental em todos os níveis de ensino e conscientização pública para preservação do meio ambiente (BRASIL, 1988).

Diante destas políticas, entende-se que o Art. 225 da Constituição Federal ao estabelecer os direitos e deveres, tanto ao poder público quanto à coletividade sobre o meio ambiente, pressupõe a efetiva participação da sociedade nos processos decisórios e de educação ambiental, sendo relevante o desenvolvimento de conhecimentos, habilidades e a reflexão crítica dos problemas ambientais, para que ocorra a participação de todos em defesa do meio ambiente. Salienta-se também a Lei 9.795/99 que institui a Política Nacional da Educação Ambiental estabelecendo políticas, ações estratégicas oficiais da educação ambiental e definições. Dentro deste contexto justifica-se a importância do projeto ter sido desenvolvido interligando as secretarias, a comunidade e as instituições educacionais, como também a associação de catadores.

As atividades promovidas foram fundamentais para realização da I Jornada Municipal de Educação Ambiental do Município de Jaguari. Com o tema "Educar para a sustentabilidade", que foi realizado no mês de Julho de 2011 com a participação de aproximadamente 120 pessoas, entre diretores, coordenadores, professores e alunos. Além das reflexões propostas em torno dos eixos: 
Crise Ambiental, Educação Ambiental e Resíduos Sólidos, ocorreram apresentações dos projetos desenvolvidos nas escolas, apresentação da associação de catadores e secretarias. Ocorreu durante a Jornada a redefinição de futuras ações na área de educação ambiental, sendo este um dos objetivos da Jornada. Diferentes situações foram evidenciadas envolvendo a preocupação com a flora e fauna, a questão dos resíduos sólidos, o consumo de água e energia, de outra forma questões de cidadania, saúde e qualidade de vida. As atividades oportunizaram que os educadores e participantes refletissem sobre as questões socioambientais, propondo e executando práticas educativas para o enfrentamento dos problemas vivenciados pela comunidade escolar.

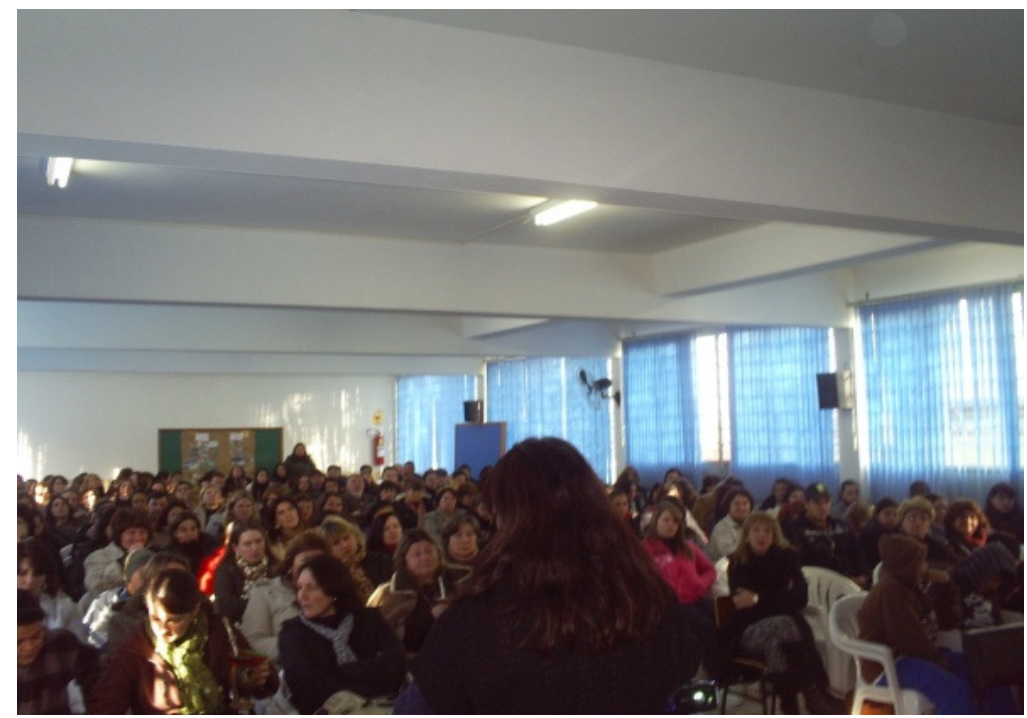

FIGURA 2: I Jornada Municipal de Educação - Julho/2011

FONTE: Lock. A.P; Kist. A.C.F.

\section{CONCLUSÕES}

Através da pesquisa realizada com base na fundamentação teórica, nas pesquisas de campo e encontros com os sujeitos do processo e o desenvolvimento de trabalhos, na abordagem crítica da educação ambiental, tendo como tema gerador os resíduos sólidos, pode-se concluir que os objetivos propostos foram alcançados com êxito.

Conclui-se, ao final da pesquisa realizada, que a educação ambiental, trabalhada através de uma concepção crítica, proporciona a formação de sujeitos críticos aptos a decidirem e atuarem, individual e coletivamente, frente aos problemas ambientais aos quais se vêem confrontados no seu dia-a-dia.

A educação ambiental na atualidade é considerada uma importante ferramenta de transformação da sociedade, proporcionando a formação de cidadãos ao exercício da cidadania, conscientes e aptos ao enfrentamento da realidade socioambiental que vivenciam. Conclui-se que para que ocorra um processo de educação ambiental e o enfrentamento das questões ambientais através 
da transformação torna-se extremamente importante a participação e envolvimento de todos os sujeitos envolvidos a partir da realidade de cada segmento. A educação ambiental deve promover a interligação da educação ambiental-formal e não-formal para que ocorra a transformação da realidade, buscando a preservação do meio ambiente, visando auxiliar na defesa do meio ambiente com sustentabilidade.

\section{REFERÊNCIAS BIBLIOGRÁFICAS}

BOFF, Leonardo. A águia e a galinha: uma metáfora da condição humana. Petrópolis: Vozes, 1997.

BRASIL. Congresso Federal. Lei no 9.795, de 27 de abril de 1999. Dispõe sobre a Educação Ambiental. Institui a política nacional de educação ambiental e dá outras providências.

BRASIL. CNUMAD. Agenda 21. 3. ed. Conferência das Nações Unidas sobre Meio Ambiente e Desenvolvimento. Brasília: Subsecretaria de Edições Técnicas do Senado Federal. 2001c. 598 p.

BRASIL. Constituição Federal, Código Civil (2002). Código do Processo Civil, Código Penal. Código de Processo penal e Legislação complementar. Barueri: São Paulo: Manole, 2003.

BRUGGER, P; Educação ou adestramento ambiental? Florianópolis: Ed. Argos: 2004. 200 p.

CARVALHO, I. C. M. Educação ambiental: a formação do sujeito ecológico. 2o ed. São Paulo: Cortez, 2006.

FREIRE, Paulo. Pedagogia do oprimido. 17 ed. Rio de Janeiro: Paz e Terra, 1987.

LAYRARGUES. P.P. ET at. Identidades da educação ambiental brasileira. Ministério do Meio Ambiente. Diretoria de Educação Ambiental; Brasília: Ministério do Meio Ambiente, 2004.156 p.

LEFF, Enrique. Pensar a complexidade ambiental. In: LEFF, Enrique (org.). A complexidade ambiental. São Paulo: Cortez, 2003.

MINISTÉRIO DO MEIO AMBIENTE- Órgão Gestor da Política Nacional de Educação Ambiental. PROFEA. Série Documentos Técnicos - 7. Brasília, 2006.

MINISTÉRIO DO MEIO AMBIENTE- Diretoria de Educação Ambiental, Ministério da Educação. Programa Nacional de Educação Ambiental - ProNEA. ed. MMA. $3^{\circ}$ ed. Brasília 2005.

TRAJBER e MENDONÇA. O que fazem as escolas que dizem que trabalham com educação ambiental? (Coleção Educação para Todos, Série Avaliação; n. 6, v. 23) Brasília: Secretaria de Educação Continuada, Alfabetização e Diversidade, 2006. 256 p.

THIOLLENT, M. Metodologia da pesquisa-ação. 7 ed. São Paulo: Cortez, 1996.

http://jaguari.rs.gov.br/. Site da Prefeitura do Município de Jaguari. Acesso em 03 de maio de 2011. 